\title{
New Ideas of Urban Natural Landscape Design
}

\author{
Shuai Yang1, 2, a Yue Huang1, b \\ 'Zhuhai College of Jilin University, Zhuhai 519041, China; \\ ${ }^{2}$ City University of Macau, Macau 999078, China. \\ a26330587@qq.com, bhuangyue13597@hotmail.com
}

Keywords: natural landscape, landscape urbanism, urban planning.

\begin{abstract}
With the development of urbanization process, the city has brought great damage to nature, and the relationship between man and nature has become increasingly uncoordinated. In today's society, the development of the city is often at the expense of the environment to win the economy and the scale of development, and now people are aware of this, slowly this process to the development, destruction, protection, and transformation of this process. While advocating the natural standard, while the city is the development of disorderly, urban design is reduced to obedience, which led to the embarrassment of the city side of the situation. Urban natural landscape design is different from the traditional urban design, not only the development of the city is based on the destruction of natural destruction and the sustainable development of the background, it is a landscape based on the improvement of urban environment and the city as a whole attempt, pay more attention to the connotation of the connotation of the city and connotation, the establishment and development of the city's internal culture, to achieve harmony with the natural environment.
\end{abstract}

\section{Introduction}

China's modern urban design principles, often to break the natural ecological balance to achieve the purpose of urban development, and for the study of urban natural landscape design, it is mainly through human efforts to continuously improve and shadow the existing biosphere situation. That is, with extremely delicate details and careful, to try to maintain the balance of natural ecology order. "Urban natural landscape" hopes that through the establishment of urban landscape system, in accordance with the laws and patterns of natural ecology to reproduce the natural environment, to maintain the natural ecological environment of the original dynamic balance, to ensure that the city's overall victory cycle, to minimize the destruction of fragile natural ecological environment by human activities and to reduce the use of all kinds of non-renewable resources, including energy, land, water resources and biological resources, by improving the efficiency of use.

In recent years, the negative impact on the ecological environment in the urbanization process has become more and more serious. The development of the city has been fully exploited in the pursuit of space. At the same time, it has neglected the connection between people and people. For the demand of space, the development of the city lacks the support of the natural landscape, while the semi-natural landscape tends to be broken, the continuity is poor and the accessibility is seriously restricted and hindered the self-repair and development of the natural ecological environment. Artificial landscape due to its urban construction and design of the external dependence, which consumes resources, including steel, resources are mostly non-renewable, so the lack of a set of independent internal self-contained operating mechanism and system, so once exhaustion and depletion of external resources will also mean that urban development is terminated, with a sustainable, non-renewable, serious destruction of resources in urban design development model and design concepts. And once the development of the city from the natural, bound to be a node in the future stagnation, so the development of the city must be back to nature, the natural elements into the urban design and planning in order to ensure the sustainability of urban development. The development of human civilization has caused irreversible effects on natural resources and ecological environment. The 
frequent occurrence of natural disasters also requires human beings to seek new breakthroughs and innovations in the process of urban development, thus transforming the situation of the past and the natural environment into a win-win situation. Therefore, the natural landscape city as an important trend in the future design and development of human cities, not only can effectively alleviate the contradiction between human and natural environment, to improve the living conditions of human beings while protecting the natural ecological environment. The natural landscape city actually has its own set of intact mechanisms for urban development that are fully capable of reaching the city's day through the exchange of internal resources and the exchange of each other. In the process of urban construction at the same time to improve the living standards of the residents, but also stressed the gradual improvement of the spirit of living standards. Change the original values of urban residents and the world outlook to form a new sense of conservation and symbiosis for the natural ecological environment. The layout and planning of the city is more reasonable and humane, to meet the different needs of different groups, classes for urban life, in strengthening the city for the use of a high degree of space at the same time, but also to strengthen the use of the width and breadth of the city, to eliminate the barriers between the human and the natural environment of the logs, to reduce the useless organization and structure within the city, so as to effectively improve the efficiency of urban development.

\section{The Idea of Landscape Urbanism}

Landscape urbanism originated in the United States in the 1970s, when the United States also faced many social problems, such as urban decentralization, industrial waste land, economic and demographic decline, ecological damage, faced with these problems, American urban landscape designers put forward the landscape as a means to reshape the urban space design theory "landscape urbanism". "Landscape urbanism" is more inclined to the ecological problems of serious urban or urban areas, the scope is relatively wide, and there are no geographical restrictions. "Landscape Urbanism" originates from the West, and its main means is the aid of the theories of landscape design and ecology. In the face of various urban problems caused by "building leading" for a long time, landscape urbanism has undoubtedly become a hot topic in the field of landscape design and architecture. In the "landscape urbanism," the beginning of the book, "landscape urbanism" to do such a full release: landscape urbanism is the current urban landscape design disciplines re-positioning, landscape elements will replace the building space as the basic unit of urban space development, which is a harmonized discipline and theoretical practice, focuses on the process of landscape growth and the reshaping of the site. Its core view is: to ecology as the starting point, from the perspective of landscape design to solve the multi-level urban problems, the organization of urban space. Thus, support the "landscape urbanism" theory of the three points, one is the theory of landscape design, the second is the theory of ecology, three is the theory of interdisciplinary and so on.

Over the years, landscape research has been deepening, and the area and scope of its use have been gradually expanded. The original target was the revival of central cities in Europe and America. Later, it has confirmed the transformation and renewal of urban industrial waste land. Today, the rapid development of the background of the new city development and other issues, but also puts forward the landscape of the guiding significance. "Landscape Urbanism", this book summed up the following three aspects of the practice: the restoration of waste land, the natural process as a form of design and landscape as a green infrastructure. Here the "abandoned", mainly refers to those abandoned industrial land, military land and slaughterhouses and so on, these sites to a certain extent have suffered pollution, and people's lives will have a certain impact. However, they also have great potential for development. In the concept of landscape, the designer restores the vitality of these sites by introducing natural elements such as plant communities. In terms of landscape urbanism, its design philosophy focuses on "design is a process." That is, in full respect for the inherent evolution of the site at the same time, do not deliberately design some artificial landscape. The landscape as a green infrastructure is to find the relationship between urban public infrastructure and natural systems, 
hoping to build a landscape with a landscape infrastructure network to complete. It includes water conservancy landscape infrastructure, traffic landscape infrastructure, agricultural production landscape infrastructure, waste management landscape infrastructure and other aspects.

\section{The Method of Urban Natural Landscape Design}

The city as a whole landscape space system, it is a natural society of a society in line with the community, with non-balance, multi-scale, level, uncertainty and randomness. "Landscape Urbanism" as mentioned earlier, it refers to the "landscape" alternative to "building" and become a new round of urban development in the process of basic media, is the green infrastructure concept theory pioneer. Its purpose and purpose of the study are more consistent, are designed to the city through the landscape to the city, and restore harmony with nature, improve the lives of urban residents and the city's air, water and other environments. The difference is that, but urban design makes the city reflect both aesthetic and humanistic characteristics, the city not only into the natural scenery but also has a regional characteristic of the landscape design.

The design of the "natural landscape city" is not intended to require specific landscape patterns, nor to stay in a static urban space pattern, instead, the design of the "natural landscape city" is focused on the protection and use of natural resources throughout the design, specifically, under the guidance of scientific and rational planning, inheritance of historical context and landscape characteristics, protection of the natural environment, highlight the national and regional style, reasonable and effective use of space, reasonable planning, integration of resources, so that the city natural landscape optimization, for the public and tourists to create a safe, comfortable and efficient urban life experience system is to obtain high quality urban life experience of the basic guarantee, and high quality, diverse urban public space, the city will bring high quality of talent and adequate development funds to promote the city's economy to achieve long-term sustainable development and prosperity.

\section{References}

[1]. SunMing, Chinese Traditional Environmental Aesthetics and Modern Urban Landscape Design, Journal of Beijing Institute of Civil Engineering and Architecture. (2004)

[2]. YangRui, On the Theory and Practice of Landscape Metropolis,Chinese Landscape Architecture .(2009) 